\title{
Intramuscular Administration of the $\beta 2$-Agonist, Formoterol, to Reduce Muscle Atrophy after Denervation
}

\section{Ong $\mathrm{AJW}^{1}$, Plant $\mathrm{DR}^{2}$, Woods $\mathrm{MG}^{3, *}$, and Lynch $\mathrm{GS}^{2}$}

${ }^{1}$ Orthodontic Unit, University of Melbourne, Australia

${ }^{2}$ Department of Physiology, University of Melbourne, Australia

${ }^{3}$ Department of Dentistry and Oral Health, Latrobe University, Australia

*Corresponding author: Woods MG, Department of Dentistry and Oral Health, Latrobe University, Australia, E-mail: m.woods@latrobe. edu.au

Received: 08 Jan, 2020 | Accepted: 18 Jan, 2020 | Published: 24 Jan, 2020

Citation: Ong AJW, Plant DR, Woods MG, Lynch GS (2020) Intramuscular Administration of the $\beta 2$-Agonist, Formoterol, to Reduce Muscle Atrophy after Denervation. Int J Dent Oral Health 6(1): dx.doi.org/10.16966/2378-7090.317

Copyright: (C) 2020 Ong AJW, et al. This is an open-access article distributed under the terms of the Creative Commons Attribution License, which permits unrestricted use, distribution, and reproduction in any medium, provided the original author and source are credited.

\section{Abstract}

Introduction: Systemic administration of $\beta 2$-agonists has been shown to retard muscle atrophy following denervation. Unfortunately, this systemic approach is often accompanied by deleterious cardiovascular side effects. It has been proposed that local intramuscular administration of a $\beta 2$ agonist to denervated muscles might prove as effective in reducing denervation atrophy, but without causing the same serious side-effects.

Aim: To determine the effects of intramuscular administration of the $\beta 2$-agonist, formoterol, on the properties and function of denervated skeletal muscle.

Method: Denervated Rat Extensor Digitorum Longus (EDL) muscles were injected with formoterol (100 $\mathrm{\mu g}$ in saline), either immediately after, or 7 days after experimental denervation. Muscle mass, fibre cross-sectional area and muscular function were assessed 7,14,21 or 28 days later. Comparisons were then made with nerve-intact and denervated-only control groups.

Results: A single intramuscular administration of formoterol into rat denervated skeletal muscle reduced both the loss of muscular force and muscle atrophy. The same intramuscular dose had little effect on muscle mass, but did reduce the loss of muscular strength. This effect was evident at 7 days, but not at 14 days. The intramuscular administration of formoterol did not reverse the effects of denervation on rat skeletal muscle. Muscle mass and muscular force was not restored to normally-innervated levels.

Conclusion: The anti-atrophic muscle effects of a single intramuscular injection of formoterol were seen to be short lived. Repeated intramuscular injections might therefore be necessary for greater efficacy and therapeutic application, to reduce muscle atrophy after denervation.

\section{Introduction}

\section{Effects of denervation}

Denervation results in changes to the structural and contractile properties of skeletal muscle. The most significant effects of denervation are atrophy, a decrease in force output and prolongation of the isometric twitch [1-3]. In response to denervation, both fast and slow-twitch muscles undergo rapid initial atrophy due to increased protein breakdown and decreased protein synthesis, followed by a more gradual loss of weight [4]. The changes in contractile properties occur indistinct early and late phases [1]. Changes in the early phase have been noted as early as 12 hours after denervation [3] and continue for the first week after nerve resection [1]. Prolonged time-to-peak tension and half-relaxation times, as well as decreased specific tetanic and tetanic tension, are the most significant changes seen during this early phase. The changes seem to be greater in fast-twitch muscles than in slow-twitch muscles $[1,2,5]$. During the late phase, 7 to 42 days after denervation, continued muscle fibre atrophy results in decreases in specific tetanic tension and tetanic tension in both fast and slowtwitch muscles $[1,5]$. It has been hypothesized that the prolongation of both time-to-peak tension and half-relaxation time could be due to changes occurring in the excitation-contraction coupling mechanism [1] associated with a decreased expression of Sarcoplasmic Reticulum $\mathrm{Ca}^{2+}$-Adenosinetriphosphatase (SERCA) $[6,7]$.

In addition to altering the contractile properties, denervation results in changes to the myofibrillar proteins. Previous workers [8-10] have demonstrated a rapid change in myosin isoforms following denervation in fast-twitch muscles, resulting in fast-to-slow transformation of the muscle. In contrast, slow-twitch muscles demonstrate slow-tofast transition of myosin isoforms [9]. These changes are thought to occur due to an alteration in the neural discharge pattern, which in turn plays a significant role in the regulation of Myosin Heavy Chain isoform (MHC) expression. Reducing neuronal activity in a slowtwitch muscle, through denervation or disuse, seems to switch on genes associated with a fast muscle phenotype. On the other hand, denervation of a fast-twitch muscle induces the conversion of the fast 
fibres to a slower muscle phenotype [10] The number of slower type I and type IIA fibres increases as a result of decreased expression of faster Type IIB and Type IIX MHC isoforms $[9,11]$.

\section{The use of systemic $\beta 2$ agonists}

$\beta 2$-adrenoceptor agonists ( $\beta 2$-agonists) such as clenbuterol were first developed for use in asthma patients, in whom they act by promoting bronchiolar smooth muscle dilation [12]. Chronic administration of $\beta 2$-agonists at high doses has been shown to result in an increase in body mass due to an increase in muscle mass [13]. A number of previous workers have demonstrated skeletal muscle hypertrophy and increased muscle strength after chronic $\beta 2$-agonist administration [14-18]. This has been attributed to $\beta 2$-adrenoceptormediated protein accretion [19], with increases in intracellular cAMP promoting both an increase in protein synthesis and a decrease in protein degradation. $\beta 2$-agonist administration results in preferential hypertrophy of Type II fibres in slow-twitch muscles, with little effect on the Type I fibres. In contrast, hypertrophy of both Type I and Type II fibres has been reported to occur in fast-twitch muscles [20]. In addition to fibre hypertrophy, chronic $\beta 2$-agonist administration also causes a dynamic shift in fibre proportions within skeletal muscle, with a reduction in the Type I MHC isoform and increased Type IIa, Type IIb, and IId/x MHC isoforms [20-24].

\section{Effect of $\beta 2$-agonists on denervated muscles}

Administration of $\beta 2$-agonists has been shown to retard atrophy in denervated muscles. For instance, Clenbuterol attenuated the loss of wet mass and protein content while increasing the cross-sectional area of denervated slow-twitch soleus muscle-but not fast-twitch EDL muscle [25] Maltin CA, et al [26] reported inhibition of denervationrelated muscle atrophy with clenbuterol treatment $(2 \mathrm{mg} / \mathrm{kg})$ in soleus muscles, with preferential hypertrophy of fast-twitch oxidative glycolytic fibres, compared with denervated controls. Those authors also reported a partial reversal of denervation-induced atrophy of rat soleus muscle following $\beta 2$-agonist administration, with almost complete restoration of muscle fibrecross-sectional area in denervated muscles to that of innervated control values. Previous authors have also reported similar increases in muscle fibre cross-sectional area, muscle mass and protein content in denervated [27,28] or unloaded [29,30] skeletal muscle after systemic $\beta 2$-agonist administration. The precise mechanism of the ameliorative effects of clenbuterol after denervation remains unknown, although evidence suggests that clenbuterol may mimic or interact with some function of innervations [31]. Clenbuterol administration has been shown to cause a large increase in protein synthesis by maintaining total RNA content and increasing mRNA translational efficiency [32]; promotion of the precocious fusion of myoblasts; repression of the myogenic regulatory factors, myoD and myogenin; and by decreasing acetylcholine receptor numbers in denervated muscle [31]. Clenbuterol may also act as mediator of protein-kinase-C activity, regulating both anabolic and catabolic pathways in muscle [33]. In addition to causing muscle hypertrophy and increasing force producing capability, $\beta 2$-agonist administration seems to hasten functional repair of regenerating skeletal muscle after myotoxic injury [34,35].

\section{Side-effects of the use of $\beta 2$-agonists in the treatment of muscle-wasting conditions}

The effects of $\beta 2$-agonists have been investigated in various animal models of muscle wasting. All of these studies involved the systemic administration of various $\beta 2$-agonists $[8,15,20,28-30,32,34]$. The authors of several clinical trials [16,36-38] have reported the successful use of systemic $\beta 2$-agonist administration in the treatment of various neuromuscular disorders, resulting in improved muscle strength. The systemic use of $\beta 2$-agonists is not without serious side-effects, however. Despite a predominance of $\beta 1$-adrenoceptors in cardiac muscle, $\beta 2$ adrenoceptors are also present, in a ratio of approximately 2:1 [15,39]. Cardiac hypertrophy, tachycardia and a decrease in cardiac output are some of the deleterious effects reported after chronic $\beta 2$-agonist administration $[15,39,40]$. These side-effects are due to the fact that the dose required to ameliorate skeletal muscle wasting often exceeds the estimated safe limit in humans [41]. In another important clinical trial involving the use of a $\beta 2$-agonist as treatment for a muscle wasting disease, unwanted side effects included muscle tremors, insomnia, cramps and nervousness [38]. Obviously, these effects would have to be minimized if $\beta 2$-agonists were to find realistic therapeutic application. If such side effects were to be reduced, it would seem reasonable to use more potent $\beta 2$-agonists or the administration of $\beta 2$-agonists in much lower doses than have previously been reported. Unfortunately, Chen and Always [42] reported only a modest attenuation of the loss in muscle mass and strength of the soleus muscle after hind limb suspension when a relatively low physiologic dose $\left(10 \mu \mathrm{g} \mathrm{kg}^{-1} / \mathrm{day}^{-1}\right)$ of clenbuterol was used. Similarly, the use of a low dose of $8 \mathrm{mg} / \mathrm{day}^{-1}$ of albuterol in patients with Duchenne and Becker muscular dystrophies elicited only moderate improvements in muscle mass and strength [43]. Ryall JG, et al. [35] demonstrated complete restoration of muscle mass and strength of both fast-twitch EDL and slow-twitch soleus muscles in adult rats to control levels, after administration of a low dose $(1.4 \mathrm{mg}$ $\left.\mathrm{kg}^{-1} / \mathrm{day}^{-1}\right)$ of fenoterol. This would seem to indicate a reversal of the muscle atrophy and weakness associated with ageing. Despite the use of this more potent $\beta 2$-agonist, cardiac hypertrophy was still evident. A later synthesized $\beta 2$-agonist, formoterol, apparently exhibits both an increased duration of action, as well as increased $\beta 2$-adrenoceptor selectivity [44] when compared with traditional $\beta 2$-agonists such as fenoterol and clenbuterol. It was thought that formoterol might therefore be promising for use as a $\beta 2$-agonist, but without the same side-effects [45].

\section{Possible effects on mandibular muscle properties and function}

The ability to influence the function of the mandibular muscles would seem to be of advantage in future attempts to control individual mandibular muscle patterns-before, during and after orthodontic treatment. While the precise relationships between the mandibular muscles and dentofacial development and treatment are not yet fully understood [46], a number of previous studies have highlighted differences in functional skeletal and muscular relationships in human subjects with different underlying facial patterns [47-49]. The effects of changes in muscular functional properties with surgical and/or pharmacological intervention have also been tested in animals [50-53] such pharmacological agents might include formoterol. Despite this previous work in animals, to date, the effects of intramuscular administration of formoterol on large skeletal muscles are yet to be reported.

With all this in mind, this study was designed to:

- Determine if a single intramuscular administration of formoterol might reduce the loss of muscle force and muscle atrophy after denervation.

- Determine if a single intramuscular administration of formoterol might increase muscle mass and reduce any loss in muscle strength after denervation.

- Determine if a single intramuscular administration of formoterol might actually reverse the effects of denervation on muscle mass and muscular force. 


\section{Methods and Materials}

\section{Animals}

All experiments were approved by the Animal Experimentation Ethics Committee of The University of Melbourne (AECC number 05076), and performed in accordance with the guidelines for Care and Use of Experimental Animals, as described by the National Health and Medical Research Council of Australia.

Adult (350-410g) male Sprague Dawley rats $(n=40)$ were housed in standard cages within a pathogen-free environment in the Biological Research Facility at The University of Melbourne. The animals were kept under a 12:12 hour light: dark cycle (light 0600-1800) with free access to food (rat chow) and water. All rats were randomly assigned to either a nerve-intact group $(n=5)$, or one of three denervated groups: no-drug $(\mathrm{n}=10)$, immediate-drug $(\mathrm{n}=10)$ or delayed-drug $(\mathrm{n}=15)$.

\section{Experimental procedure (Figure 1)}

The rats were anaesthetized with Ketamine: Xylazinesterile saline $(2 \mathrm{~mL} / \mathrm{kg}$ body mass) via intraperitoneal injections, rendering them unresponsive to tactile stimuli. For all denervated rats, an incision was made in the mid-thigh region of the right side to expose the sciatic nerve. The nerve was then cut, with care taken not to damage adjacent muscles and to ensure that the resected nerve ends were not in contact. For the animals in the two drug groups, the right Extensor Digitorum Longus (EDL) muscle was injected intramuscularly with formoterol

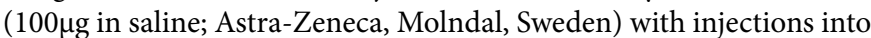
the distal, proximal and mid-belly regions, using a 26-gauge needle. After injection, each wound was closed with Michel clips (Aesculap, Tuttlingen, Germany). Animals assigned to the immediate-drug group had the muscle injected with formoterol at the time of sciatic nerve resection. Animals assigned to the delayed-drug group had the muscle injected with formoterol 7 days after nerve resection.

\section{Evaluation of muscle function (Figure 2)}

The contractile properties of the denervated EDL muscles in the no-drug and immediate-drug groups were assessed at 7 and 14 days after sciatic nerve resection. Those in the delayed-drug group were evaluated at 7, 14 and 21 days after formoterol administration (i.e. 14,21 and 28 days after denervation). On the day of each experiment, animals were anaesthetized deeply with pentobarbital sodium (Nembutal, Rhone Merieux, Pinkenba, Queensland, Australia; $60 \mathrm{mg} / \mathrm{kg}$ i.p.), with supplemental doses administered as necessary to maintain a depth of anesthesia which would prevent responses to tactile stimuli. The EDL muscle was surgically exposed and the distal and proximal tendons tied with braided silk sutures (3-0, Pearsalls Sutures, Somerset, UK). The nerve and blood supplies to the muscle remained intact throughout the dissection and were severed just prior to excision, in order to maintain optimum muscle viability for measurement of contractility. The excised muscle was blotted once on filter paper (Whatman no.1 filter paper, Maidstone, UK) and transferred to a custom-built Plexiglas organ bath filled with KrebsRinger solution (in mM:1.37 NaCl, $24 \mathrm{NaHCO}_{3}, 11 \mathrm{D}$-glucose, $5 \mathrm{KCl}$, $2 \mathrm{CaCl}_{2}, 1 \mathrm{NaH}_{2} \mathrm{PO}_{4} \mathrm{H}_{2} \mathrm{O}, 0.487 \mathrm{MgSO}_{4} \cdot 7 \mathrm{H}_{2} \mathrm{O}, 0.293 d$-tubocurarine chloride; $\mathrm{pH}$ 7.4) that was bubbled with Carbogen $\left(5 \% \mathrm{CO}_{2}\right.$ in $95 \%$ $\mathrm{O}_{2}$, BOC Gases, Preston, Victoria, Australia) and thermostatically maintained at $25^{\circ} \mathrm{C}$. These conditions have been demonstrated to facilitate optimal oxygen diffusion throughout the muscle and stability of functional measurements, in vitro [15,54]. Upon completion of EDL muscle excision, the thoracic region was exposed and the rats sacrificed by cardiac excision.

The muscle was aligned horizontally within the organ bath and secured between a fixed pin and the lever arm of a dual-mode servomotor (305-LR, Aurora Scientific, Aurora, Ontario, Canada) with two platinum electrodes flanking the length of the muscle preparation. The muscle was then stimulated with supramaximal square-wave pulses $(0.2 \mathrm{~ms}$ duration) that were amplified (Ebony, power amplifier EP500B, Audio Assemblers, Campbellfield, Victoria, Australia) to ensure sufficient current intensity to produce maximum isometric tetanic contraction. The servomotor and stimulation operations were controlled by custom-written applications (D.R Stom Software solutions, Ann Arbor, MI, USA) of LabView Software (National Instruments, Austin, TX, USA), driving a personal computer with

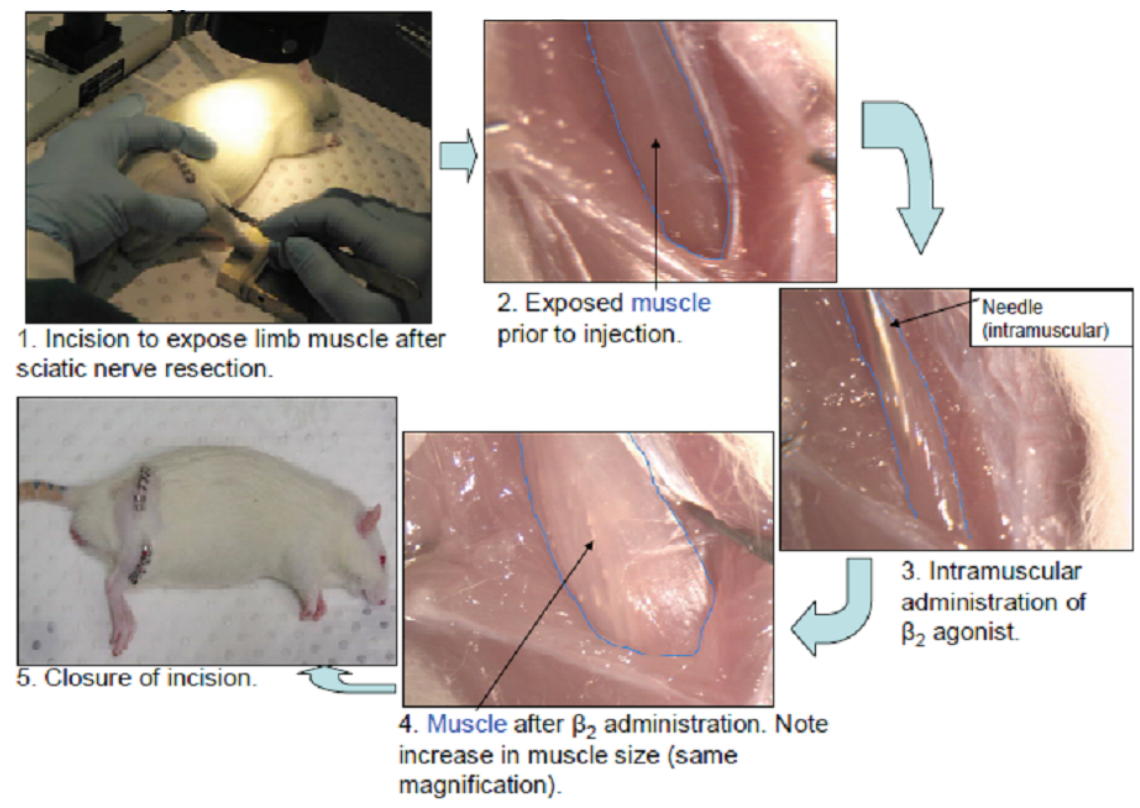

Figure 1: Methods of $\beta_{2}$-agonist administration. 

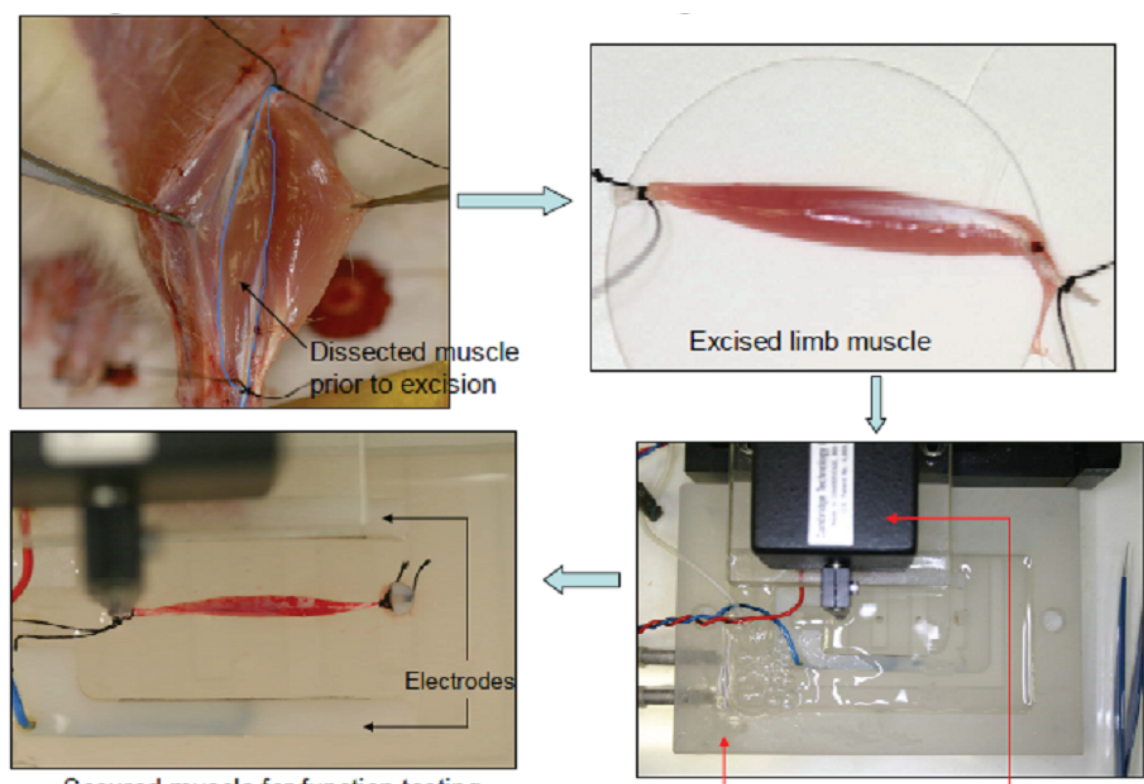

Secured muscle for function testing

Organ bath and Servomotor

Figure 2: Procedure for testing of muscle function.

an on-board controller (PCI-MIO-16XE-10, National Instruments) interfaced with the servomotor controller hardware (6650LR DualMode Lever System, Aurora Scientific).

The muscle was stimulated to produce isometric twitch responses at different muscle lengths. Optimum muscle length (Lo) was determined from the length at which maximum isometric twitch force $(\mathrm{Pt})$ was obtained. Optimum fibre length (Lf) was calculated by multiplying Lo by 0.44 , the accepted fibre-length to muscle ratio for rat EDL muscle [55]. A frequency-force curve was established by stimulating the muscle at frequencies of 10,20,30,40,50, 75,100,150 and $200 \mathrm{~Hz}$ with a 2 minute rest period between each stimulus to prevent fatigue. Maximum isometric tetanic force (Po) was determined from the plateau of the frequency-force curve. The muscle was then stimulated once every 5 seconds at optimum length, voltage and frequency, with a stimulation-duration of 350 milliseconds, for a total of 4 minutes. Po was also determined 5 minutes after the completion of the fatigue protocol, to assess the recovery of maximum force-producing capacity after fatigue.

Upon completion of the functional measurements, the muscle was carefully blotted on filter paper (Whatman no.1 filter paper, Maidstone, $\mathrm{UK})$, trimmed of its tendons and adherent connective tissue, and weighed on an analytical balance. Muscle-fibrecross-sectional Area (CSA) was calculated by taking into account muscle mass, optimum fibre length (Lf) and $1.06 \mathrm{~g} / \mathrm{m}^{3}$, the density of mammalian skeletal muscle [56]. Specific or normalised force (sPo) was calculated as the maximum force per unit muscle fibre CSA. Immediately after weighing, each muscle was tied to a glass capillary tube at optimum muscle length (Lo), snap-frozen in isopentane, then cooled in liquid nitrogen and stored at $-80^{\circ} \mathrm{C}$ for later histological examination.

\section{Histological examination}

Each frozen muscle sample was sectioned transversely, as close to the mid-belly region as possible, using a cryostat microtome at $-20^{\circ} \mathrm{C}$, in order to obtain $8 \mu \mathrm{m}$-thick sections. Five serial sections were placed onto uncoated glass microscope slides and stained with haematoxylin and eosin ( $\mathrm{H}$ and $\mathrm{E})$ to determine general muscle architecture and muscle fibre cross-sectional area. Images of the muscles were acquired with a digital camera (Spot model 1.3.0, Diagnostic Instruments, Sterling Heights, MI, USA) attached to an upright microscope (Olympus B $\times 51$ light microscope, Olympus, Tokyo, Japan) at X20 magnification. The images were then analysed in a single-blinded manner, using a calibrated Analytical Imaging Station (AIS, v6.0, Imaging Research, Ontario, Canada). The mean cross-sectional areas of individual fibres were calculated by interactive determination of the circumference of $\geq 150$ adjacent fibres from the centre of each muscle section.

\section{Statistical analysis}

All measurement values were expressed as mean \pm standard error of the mean, unless otherwise specified. Effects in the two formoterol drug groups at each time point were compared (StatView Statistical Analysis package) with the nerve-intact and no-drug groups by using a two-way analysis of variance (ANOVA), then Fisher's least significant difference post hoc multiple comparison test. Significance for differences in the means for different groups was set at $\mathrm{P}<0.05$.

\section{Results}

\section{Muscle mass and muscle-fibre cross-sectional area}

Denervation resulted in a progressive decrease in muscle mass for both no-drug and immediate-drug groups, with formoterol administration seeming to have little effect on muscle mass (Table 1a). Despite the lack of any significant differences in muscle mass at each time point, fibre CSA was $31 \%$ and $34 \%$ greater in the immediatedrug group at 7 and 14 days, respectively $(\mathrm{P}<0.05$, Tables $1 \mathrm{a}$ and $1 \mathrm{~b})$. Compared with the 14 day delayed-drug group, muscle mass was approximately $12 \%$ greater than in the 21 day group $(\mathrm{P}<0.05)$. No significant differences in muscle fibre CSA were noted in the delayeddrug group at these time points (Table 2). Selected Haematoxylin and Eosin-stained sections are shown in figures 3-7. 
Table 1a: Mean muscle mass and fibre cross-sectional area for no-drug and immediate-drug groups, 7 days after denervation.

\begin{tabular}{|c|c|c|}
\hline & \multicolumn{2}{|c|}{7 days } \\
\hline \multicolumn{1}{|c|}{ Treatment } & No-drug & Immediate-drug \\
\hline Group size $(\mathrm{n})$ & 5 & 5 \\
\hline Muscle mass (mg) & $155.9(2.5)$ & $164.6(4.7)$ \\
\hline Fibre CSA ym ${ }^{2}$ & $265.3(17.2)$ & $349.4(26.4)^{*}$ \\
\hline
\end{tabular}

${ }^{*} \mathrm{P}<0.05$-difference between the no-drug and immediate-drug groups

Table 1b: Mean muscle mass and fibre cross-sectional area for no-drug and immediate-drug groups, 14 days after denervation.

\begin{tabular}{|l|c|c|}
\hline & \multicolumn{2}{|c|}{ 14 days } \\
\hline \multicolumn{1}{|c|}{ Treatment } & No-drug & Immediate-drug \\
\hline Group size $(\mathrm{n})$ & 5 & 5 \\
\hline Muscle mass $(\mathrm{mg})$ & $143.8(4.1)$ & $142.3(10.5)$ \\
\hline Fibre CSA ym ${ }^{2}$ & $203.7(9.1)$ & $274.4(13.8)^{*}$ \\
\hline
\end{tabular}

* $P<0.05$-difference between the no-drug and immediate-drug groups

\section{Muscle contractile properties}

Denervation only (no-drug group) resulted in a progressive decline in maximum isometric tetanic force (Po), when compared with the nerve-intact controls, when measured 7 and 14 days after denervation. For instance, the no-drug denervated group Po at day 7 was approximately $40 \%$ lower than that of the nerve-intact controls. The Po of no-drug denervated muscle at day 14 was approximately $45 \%$ of that for the nerve-intact group (Tables $3 \mathrm{a}$ and $3 \mathrm{~b}$ ). Muscles from the immediate-drug group showed a $32 \%$ decrease in Po at day 7 and a $47 \%$ decrease at day 14 . (Tables $3 a$ and 3b). The decrease in Po due to denervation (no-drug) was diminished with the formoterol administration by $8 \%$ at 7 days after denervation $(\mathrm{P}<0.05)$. No difference was found between the groups, however, at 14 days (Tables $3 \mathrm{a}$ and $3 \mathrm{~b}$ ). In the delayed-drug group, the Po was decreased $47 \%, 48 \%$ and $56 \%$ when compared with nerve-intact muscles, 7,14 and 21 days after formoterol administration (Table 4) (actually corresponding to 14,21 and 28 days after the original denervation).

The normalised force (sPo) of the EDL muscles for the no-drug group was $36 \%$ lower than that for the nerve-intact controls at day 7 after denervation and $32 \%$ lower at day 14 . Changes in the maximum isometric tetanic force ( $\mathrm{Po}$ ) of the immediate-drug group at 7 days were mirrored by a corresponding increase in the sPo of the muscle in those immediate-drug animals, compared with the no-drug group $(\mathrm{P}<0.05)$. This relationship was no longer evident at day 14 .

Denervation Prolonged Time to Peak Tension (TPT) of EDL muscles, with TPT for the no-drug denervated group being $19 \%$ greater than that for the nerve-intact group at day 7, and 63\% greater at 14 days (Tables $3 \mathrm{a}$ and $3 \mathrm{~b}$ ). Formoterol administration prolonged TPT, being $40 \%$ greater in the immediate-drug group compared with the nerve-intact group at day 7 and $17 \%$ greater than for the no-drug group $(\mathrm{P}<0.05)$. The observed difference in TPT values between the no-drug and immediate-drug groups was not evident at day 14 (Tables $3 a$ and $3 b$ ). The TPT of the delayed-drug group was not different to that of the no-drug group (Tables $3 \mathrm{a}$ and $3 \mathrm{~b}$ ).

The half relaxation time ( $1 / 2 \mathrm{RT})$ also increased after denervation, with no-drug muscles showing an increase in $1 / 2$ RT of $38 \%$, when compared with that of nerve-intact muscles at day 7 (Table 3a) and a $129 \%$ increase in $1 / 2$ RT by day 14 (Table $3 \mathrm{~b}$ ). In the immediatedrug group, the $1 / 2 \mathrm{RT}$ was increased by $81 \%$ and $31 \%$ at day 7 when compared with the nerve-intact and no-drug groups, respectively. There were no differences in 1/2 RT for the no-drug and immediatedrug groups at day 14. No significant difference was observed when the no-drug muscles were compared with the delayed-drug group at any time point.

\section{Discussion}

The most important finding of this study was that immediate intramuscular injection of the $\beta 2$-agonist, formoterol, into denervated EDL muscles ameliorated the loss in force-producing capacity by reducing the rate of muscle fibre atrophy. Both Po and muscle fibre CSA were found to be greater in formoterol-treated denervated muscles when compared with no-drug denervated muscles. This would support the hypothesis that intramuscular administration of a $\beta 2$-agonist can actually reduce the effects of denervation.

Denervation, on its own, resulted in loss of muscle mass, atrophy of the muscle fibres and an accompanying decrease in Po. The majority of the loss in muscle strength occurred within the first 7 days after denervation. This rate of loss in muscle strength is consistent with the changes in rate of protein turnover observed by Goldspink DF, et al. [57] during the first 7 days after denervation. The decline in sPo was not, however, consistent with the changes in fibre CSA in the muscles from the no-drug and immediate-drug groups. This indicates that

Table 2: Mean muscle mass and fibre cross-sectional area for no-drug and delayed-drug groups, 14 days onwards after denervation.

\begin{tabular}{|c|c|c|c|c|}
\hline \multirow{2}{*}{ Treatment } & \multicolumn{2}{|c|}{ No-drug } & \multicolumn{2}{c|}{$\begin{array}{c}\text { Delayed-drug days after } \\
\text { denervation }\end{array}$} \\
\cline { 2 - 5 } & 14 & 14 & 21 & 28 \\
\hline Group size (n) & 5 & 5 & 5 & 5 \\
\hline $\begin{array}{c}\text { Muscle mass } \\
(\mathrm{mg})\end{array}$ & $143.8(4.1)$ & $122.7(3.9)$ & $138.3(2.6)^{*}$ & $123.4(4.5)$ \\
\hline Fibre CSA ym & $203.7(9.1)$ & $222.3(21.8)$ & $227.6(19.7)$ & $202.5(24.0)$ \\
\hline
\end{tabular}

$* P<0.05$-difference between muscle mass at day 21 , compared with days 14 and 28

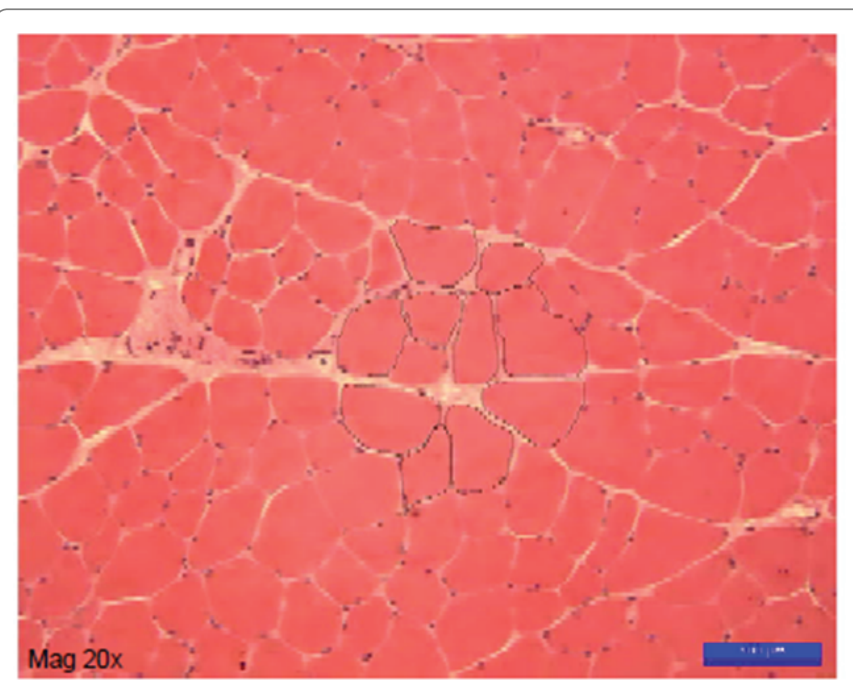

Note: Large initial fibre size

Figure 3: Appearance of Undamaged limb muscle.. 


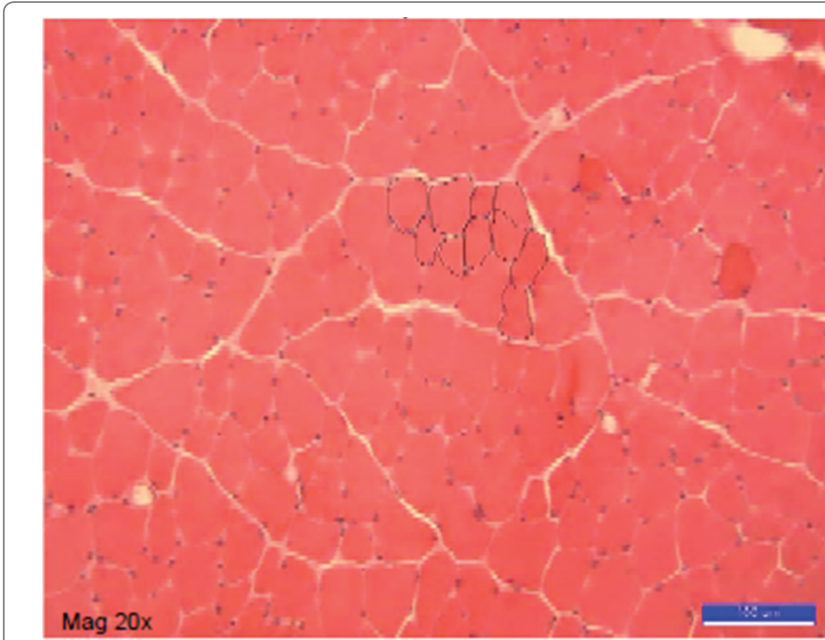

Note: Decrease in fibre size without $\beta_{2}$-agonist administration

Figure 4: Damaged but untreated control limb muscle-appearance 7 days later.

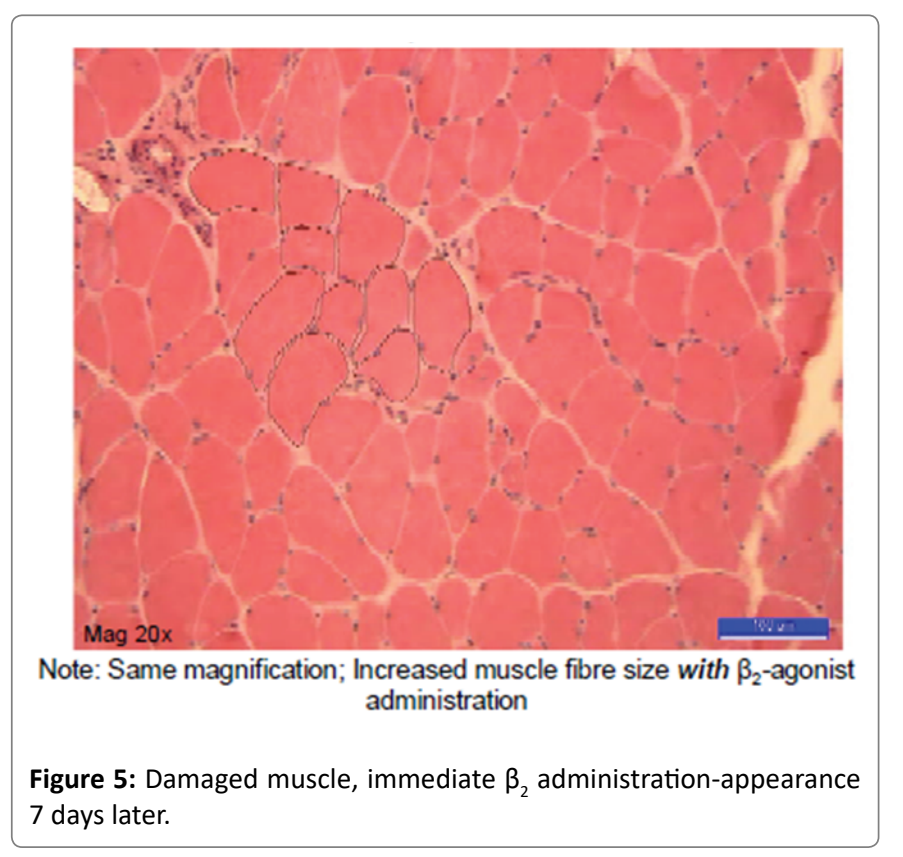

atrophy of the muscle fibres, alone, may not be totally responsible for any observed decline in mass and strength.

Despite the approximately 8 per cent improvement in Po in the immediate-drug group, the Po was still 32 per cent lower than for the nerve-intact control group. The muscles of the immediate-drug group did however exhibit a clear reduction in the denervation-induced atrophy, when compared with no-drug denervated muscles. The anti-atrophic effects of formoterol appear then to be short-lived and, despite the muscle fibre CSA still being greater in the immediate-drug group at day 14, the Po was not increased.

The increase in muscle fibre CSA observed in the immediate-drug group is similar to that found in other studies in which $\beta 2$-agonists have been administered systemically [26-28], except for the fact that the observed increase in fibre CSA was not associated with a similar increase in muscle mass [26-28,58].

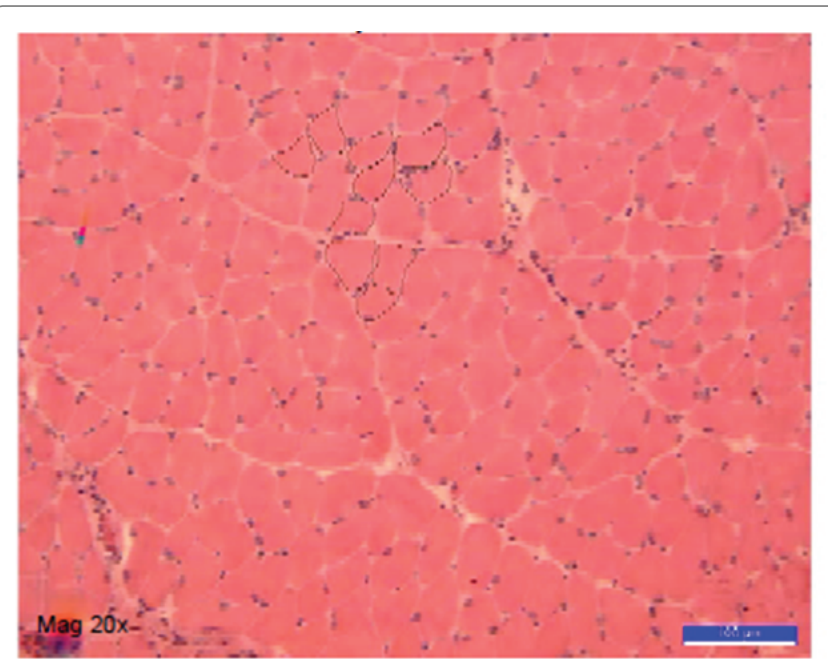

Note: Increased muscle atrophy and inflammation with continued denervation size without $\beta_{2}$-agonist administration

Figure 6: Damaged but untreated control limb muscle-appearance 14 days later.

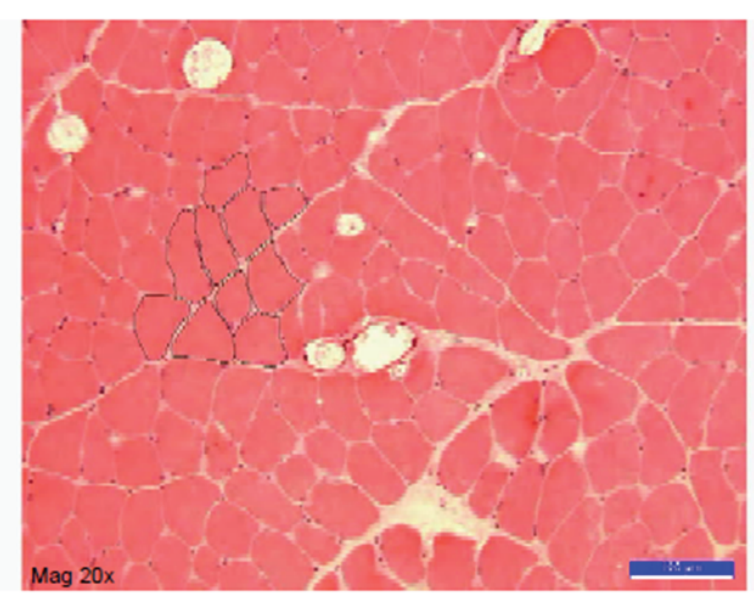

Note: At 14 days, measured fibre cross-sectional area is still larger than untreated muscles

Figure 7: Damaged but untreated control limb muscle-appearance 14 days later.

The increases in contractile strength and muscle fibre CSA observed in both formoterol drug groups contrast with the reports of Zeman RJ, et al. [20] of there being no effect of systemically-administered clenbuterol on denervated rat EDL muscle. It is possible that the greater efficacy, affinity and $\beta 2$-adrenoceptor selectivity of formoterol might have produced a greater cellular response than clenbuterol [59] Formoterol administration does appear to improve both the total muscular force and the force per unit of muscle CSA. This suggests that some fibre hypertrophy and/or reduced fibre loss had occurred.

The exact mechanism of action for the anti-atrophic effects of formoterol has yet to be determined. Changes observed following $\beta 2$-agonist administration are thought to be due to an increased rate of protein synthesis, a reduced rate of protein breakdown, or a combination of both [19]. Stimulation of $\beta$-adrenoceptors results in increased cyclic AMP (cAMP) production, activating the cAMPdependent protein kinase, which targets the enzymes: calpain and 
Table 3a: Mean contractile muscle measurements for nerve-intact, nodrug and immediate-drug groups, 7 days after denervation.

\begin{tabular}{|l|c|c|c|}
\hline \multirow{2}{*}{\multicolumn{1}{|c|}{ Group }} & \multicolumn{3}{|c|}{7 days } \\
\cline { 2 - 4 } & Nerve-intact & No-drug & Immediate-drug \\
\hline $\mathrm{Pt}(\mathrm{mN})$ & $916.6(17.3)$ & $1027.5(73.4)$ & $1119.1(29.8)$ \\
\hline $\mathrm{TPT}(\mathrm{ms})$ & $26.4(1.3)$ & $31.5(1.2)$ & $37.0(0.7)^{*}$ \\
\hline $1 / 2 \mathrm{RT}(\mathrm{ms})$ & $26.4(1.7)$ & $36.5(1.6)$ & $48.0(1.6)^{*}$ \\
\hline $\mathrm{dPt} / \mathrm{dt}(\mathrm{mN} / \mathrm{ms})$ & $79.0(2.6)$ & $77.5(4.2)$ & $80.1(2.4)$ \\
\hline $\mathrm{Po}(\mathrm{mN})$ & $2646.8(36.4)$ & $1573.5(87.4)$ & $1801.9(78.2)^{*}$ \\
\hline $\mathrm{sPo}\left(\mathrm{kN} / \mathrm{m}^{2}\right)$ & $246.3(6.4)$ & $159.7(9.6)$ & $180.1(3.9)^{*}$ \\
\hline
\end{tabular}

* $\mathrm{P}<0.05$-significant difference between no-drug and immediate-drug groups

Pt-Maximum Isometric Twitch Force

TPT-Time to Peak Tension

$1 / 2$ RT-Half Relaxation Time

Po-Maximum Isometric Tetanic Force

sPo-Specific Normalised Force

Table 3b: Mean contractile muscle measurements for No-drug, Immediate-drug and Delayed-drug groups, 14 days after denervation.

\begin{tabular}{|l|c|c|c|}
\hline \multirow{2}{*}{\multicolumn{1}{c|}{ Group }} & \multicolumn{3}{|c|}{14 days } \\
\cline { 2 - 4 } & No-drug & Immediate-drug & Delayed-drug \\
\hline $\mathrm{Pt}(\mathrm{mN})$ & $855.9(34.8)$ & $838.0(18.2)$ & $887.9(38.9)$ \\
\hline $\mathrm{TPT}(\mathrm{ms})$ & $43.1(1.9)$ & $40.1(0.9)$ & $41.8(1.6)$ \\
\hline $1 / 2 \mathrm{RT}(\mathrm{ms})$ & $60.7(1.1)$ & $58.2(1.2)$ & $69.1(1.6)$ \\
\hline $\mathrm{dPt} / \mathrm{dt}(\mathrm{mN} / \mathrm{ms})$ & $63.25(2.5)$ & $63.7(2.3)$ & $69.7(1.5)$ \\
\hline $\mathrm{Po}(\mathrm{mN})$ & $1444.5(53.9)$ & $1406.5(39.9)$ & $1390.4(31.2)$ \\
\hline $\mathrm{sPo}(\mathrm{kN} / \mathrm{m} 2)$ & $169.8(7.1)$ & $170.1(7.3)$ & $196.0(3.2)^{*}$ \\
\hline
\end{tabular}

* $P<0.05$-Significant difference between no-drug and delayed-drug groups

calpastatin. These enzymes are, in turn, responsible for modulating the activity of the intracellular $\mathrm{Ca}^{2+}$-dependent proteolytic pathways. Busquets S, et al. [59] however, suggested that the main antiproteolytic action of formoterol may be based on the inhibition on the ATP ubiquitin-dependent proteolytic system. Whatever the case, both sets of authors agreed that the effects of $\beta 2$-agonists are likely to due to some stimulation of protein synthesis [19,59].

Denervation is also associated with an accumulation of the myoD and myogenin transcripts which regulate the transcription of tissue-specific genes during skeletal muscle differentiation [36]. The expression of these transcripts is controlled by normal innervation, with low levels of both transcripts found in normal innervated muscles. There is evidence to show a repression of both myoD and myogenin following $\beta 2$-agonist administration to denervated muscles. This would suggest either a mimicking of innervation, or the interaction of the $\beta 2$-agonist with some other function of innervations [36], as being other possible mechanisms for the anti-atrophic effects.

A marked change in the contractile properties of EDL muscle was noted following the original denervation injury. Both the observed increase in TPT for isometric twitch contraction and the 1/2 RT in denervated muscles were similar to those reported from other studies $[1,5,60]$ They are thought to be due to transient changes occurring in membrane electrical properties, within one to two days after denervation [1] Denervation injuries to EDL muscles have been shown to result in a rapid change in muscle phenotype, via a shift to an increased myosin heavy chain expression of slow isoforms (Type I and IIA) and a decreasing expression of the faster Type IIB and IIX
Table 4: Mean contractile muscle measurements for nerve-intact and delayed-drug groups, 14, 21 and 28 days after denervation.

\begin{tabular}{|l|c|c|c|c|}
\hline \multirow{2}{*}{ Group } & & & $\begin{array}{c}\text { Delayed-drug } \\
\text { days after } \\
\text { denervation }\end{array}$ & \\
\cline { 2 - 5 } & Nerve-intact & 14 days & 21 days & 28 days \\
\hline $\mathrm{Pt}(\mathrm{mN})$ & $916.6(17.3)$ & $887.9(38.9)$ & $814.9(57.8)$ & $643.8(40.1)$ \\
\hline $\mathrm{TPT}(\mathrm{ms})$ & $26.4(1.3)$ & $41.8(1.6)$ & $44.5(1.1)$ & $45.9(2.1)$ \\
\hline $\mathrm{1} / 2 \mathrm{RT}(\mathrm{ms})$ & $26.4(1.7)$ & $69.1(1.6)$ & $75.2(8.9)$ & $71.2(5.2)$ \\
\hline $\begin{array}{l}\mathrm{dPt} / \mathrm{dt} \\
(\mathrm{mN} / \mathrm{ms})\end{array}$ & $79.0(2.6)$ & $69.7(1.5)$ & $63.4(4.6)$ & $48.6(2.8)$ \\
\hline $\mathrm{Po}(\mathrm{mN})$ & $2646.8(36.4)$ & $1390.4(31.2)$ & $1355.2(79.4)$ & $\begin{array}{c}1161.0 \\
(68.6)\end{array}$ \\
\hline sPo (kN/m2) & $246.3(6.4)$ & $196.0(3.2)$ & $171.4(10.1)$ & $165.0(7.3)$ \\
\hline
\end{tabular}

isoforms [8]. These changes have, however, been shown to occur after a delay of approximately 2 weeks $[1,10]$. Hence, they would be unlikely to be the main cause of the observed increases in TPT and 1/2 RT found in this study. A reduction in the level of sarcoplasmic reticulum $\mathrm{Ca}^{2+}$-adenosinetriphosphatase, due to suppressed specific $\mathrm{Ca}^{2+}$ ATPase activity following denervation [7], might compromise $\mathrm{Ca}^{2+}$ sequestration and, in turn, contribute to the observed changes in TPT and 1/2 RT. The increases in both these measurements could also be due to changes in the excitation-contraction coupling mechanism [1].

The observed greater increase in TPT following formoterol administration in the immediate-drug group would suggest some alteration in the $\mathrm{Ca}^{2+}$-handling properties of muscle. Conflicting results exist regarding the effects of $\beta 2$-agonist administration on the $\mathrm{Ca}^{2+}$ sensitivity in fast-twitch EDL fibres. While continuous administration of $\beta 2$-agonists has been reported to decrease the sensitivity of the contractile apparatus to $\mathrm{Ca}^{2+}[14]$, a similar decrease has not been seen with single administration [24]. A continuouslyraised intracellular $\mathrm{Ca}^{2+}$, due to a clenbuterol-induced increase in the rate of passive $\mathrm{Ca}^{2+}$ leak from the sarcoplasmic reticulum has previously been demonstrated [24], and elevated intracellular $\mathrm{Ca}^{2+}$ levels have been shown to cause damage to the excitation-contraction coupling in EDL muscle [61]. A combination of the change in $\mathrm{Ca}^{2+}$ sensitivity, and damage to the excitation-contraction coupling of the muscle following formotorol administration, might then explain the variation observed in TPT and 1/2 RT values for the immediate-drug group in this study. So, overall it can be seen that, while a single intramuscular injection of formoterol was able to reduce muscular atrophy following denervation, the effects were short-lived, with both muscle mass and Po being similar to no-drug denervated-only muscles by day [14]. Future studies might then involve the assessment of whether repeated intramuscular injections might help with denervation-induced muscle atrophy in the longer term.

\section{Conclusions}

Taking into account the limitations of any laboratory animal study, the following conclusions can be drawn:

- A single intramuscular administration of formoterol into rat denervated skeletal muscle reduces both the loss of muscular force and muscle atrophy.

- A single intramuscular administration of formoterol into rat denervated skeletal muscle has little effect on muscle mass, but does reduce the loss of muscular strength. This effect is likely to be evident at 7 days, but not at 14 days. 
- The intramuscular administration of formoterol does not reverse the effects of denervation in rat skeletal muscle. Muscle mass and muscular force is not likely to be restored to normally-innervated levels.

- The anti-atrophic muscle effects of a single intramuscular injection of formoterol are likely to be short-lived. Repeated intramuscular injections might therefore be necessary for greater efficacy and therapeutic application, if attempting to reduce muscle atrophy after denervation.

\section{Acknowledgements}

This work was supported in part by the Australian Society of Orthodontists' Foundation for Research and Education and the Melbourne Centre for Facial Disorders.

\section{Conflict of Interest}

No known conflict of interest.

\section{Funding}

Australian Society of Orthodontists' Foundation for Research and Education and Melbourne Centre for Facial Disorders.

\section{Ethics}

All experiments were approved by the Animal Experimentation Ethics Committee of the University of Melbourne (AECC number 05076) and performed in accordance with the guidelines determined by the National Health and Medical Research Council'.

\section{References}

1. Finol HJ, Lewis DM, Owens R (1981) The effects of denervation on contractile properties of rat skeletal muscle. J Physiol 319: 81-92.

2. Gundersen K (1985) Early effects of denervation on isometric and isotonic contractile properties of rat skeletal muscle. Acta Physiol Scand 124: 549-555.

3. Gutmann E, Melincha J, Syrový I (1972) Contraction properties and ATPase activity in fast and slow muscle of the rat during denervation. Exp Neurol 36: 488-497.

4. Goldspink DF (1976) The effects of denervation on protein turnover of rat skeletal muscle. Biochem J 156: 71-80.

5. Dulhunty AF (1985) Excitation-contraction coupling and contractile properties in denervated rat EDL and soleus muscles. J Musc Res Cell Motility 6: 207-225.

6. Lewis DM (1972) The effect of denervation on the mechanical and electrical properties of fast and slow mammalian twitch muscle. $J$ Physiol 222: 51-75.

7. Schulte L, Peters D, Taylor J, Navarro J, Kandarian S (1994) Sarcoplasmic reticulum $\mathrm{Ca}^{2+}$ pump expression in denervated skeletal muscle. Am J Physiol 267: C617-C622.

8. Bobinac D, Malnar-Dragojevic D, Bajek S, Soic-Vranic T, Jerkovic R (2000) Muscle fiber type composition and morphometric properties of denervated rat extensor digitorum longus muscle. Basic Sci 41: 294-307.

9. Bozzo C, Spolaore B, Toniolo L, Stevens L, Bastide B, et al. (2005) Nerve influence on myosin light chain phosphorylation in slow and fast skeletal muscles. FEBS J 272: 5771-5785.

10. Windisch A, Gundersen K, Szabolcs MJ, Gruber H, Lømo T (1998) Fast to slow transformation of denervated and electrically-stimulated rat muscle. J Physiol 510: 623-632.
11. Walters EH, Stickland NC, Loughna PT (2000) The expression of myogenic regulatory factors in denervated and normal muscles of different phenotypes. J Musc Res Cell Motility 21: 647-653.

12. Ball DI, Brittain RT, Coleman RA, Denyer LH, Jack D (1991) Salmeterol, a novel, long-acting beta 2-adrenoceptor agonist: characterization of pharmacological activity in vitro and in vivo. Br J Pharmacol 104: 665-671.

13. Emery PW, Rothwell NJ, Stock MJ, Winter PD (1984) Chronic effects of beta 2-adrenergic agonists on body composition and protein synthesis in the rat. Biosci Rep 4: 83-91.

14. Lynch GS, Hayes A, Campbell SP, Williams DA (1996) Effects of beta 2 -agonist administration and exercise on contractile activation of skeletal muscle fibers. J Appl Physiol 81: 1610-1618.

15. Ryall JG, Gregorevic P, Plant DR, Sillence MN, Lynch GS (2002) Beta 2-agonist fenoterol has greater effects on contractile function of rat skeletal muscles than clenbuterol. Am J Physiol Regul Integr Comp Physiol 283: R1386-R1394.

16. Martineau L, Horan MA, Rothwell NJ, Little RA (1992) Salbutamol, a beta 2-adrenoceptor agonist, increases skeletal muscle strength in young men. Clin Sci (Lond) 83: 615-621.

17. Choo JJ, Horan MA, Little RA, Rothwell NJ (1992) Anabolic effects of clenbuterol on skeletal muscle are mediated by beta 2-adrenoceptor activation. Am J Physiol Endocrinol Metab 263: E50-E56.

18. MacLennan PA, Edwards RHT (1989) Effects of clenbuterol and propanolol on muscle mass. Biochem J 264: 573-579.

19. Navegantes LCC, Migliorini RH, Kettelhut IC (2002) Adrenergic control of protein metabolism in skeletal muscle. Curr Opin Clin Nutr Metab Care 5: 281-286.

20. Zeman RJ, Ludemann R, Easton TG, Etlinger JD (1988) Slow to fast alterations in skeletal muscle fibers caused by clenbuterol, a beta 2-receptor agonist. Am J Physiol 365: E726-E732.

21. Rajab P, Fox J, Riaz S, Tomlinson D, Ball D, et al. (2000) Skeletal muscle myosin heavy chain isoforms and energy metabolism after clenbuterol treatment in the rat. Am J Physiol Regul Integr Comp Physiol 279: R1076-R1081.

22. Cairns SP, Dulhunty AF (1993) Beta-adrenergic Potentiation of E-C Coupling Increases Force in Rat Skeletal Muscle. Muscle Nerve 16: 1317-1325.

23. Prakash YS, Van Der Heijden HF, Gallant EM, Sieck GC (1999) Effect of Beta-Adrenoceptor Activation on $\left[\mathrm{Ca}^{2+}\right] \mathrm{i}$ Regulation in Murine Skeletal Myotubes. Am J Physiol 276: C1038-C1045.

24. Bakker AJ, Head SI, Wareham AC, Stephenson DG (1998) Effect of Clenbuterol on Sarcoplasmic Reticulum Function in Single Skinned Mammalian Skeletal Muscle Fibers. Am J Physiol 274: C1718-C1726.

25. Zeman RJ, Ludemann R, Etlinger JD (1987) Clenbuterol, a Beta 2-agonist, Retards Atrophy in Denervated Muscles. Am J Physiol 252: E152-E155.

26. Maltin CA, Reeds PJ, Delday MI, Hay SM, Smith FG, et al. (1986) Inhibition and Reversal of Denervation-Induced Atrophy by the Beta-Agonist Growth Promoter, Clenbuterol. Biosci Rep 6: 811-818.

27. Soic-Vranic T, Bobinac D, Bajek S, Jerkovic R, Malnar-Dragojevic D, et al. (2005) Effect of Salbutamol on Innervated and Denervated Rat Soleus Muscle. Braz J Med Biol Res 38: 1799-1805.

28. Cockman MD, Jones MB, Prenger MC, Sheldon RJ (2001) Magnetic Resonance Imaging of Denervation-Induced Muscle Atrophy: Effects of Clenbuterol in the Rat. Muscle Nerve 24: 1647-1658. 
29. Herrera NM Jr, Zimmerman AN, Dykstra DD, Thompson LV (2001) Clenbuterol in the Prevention of Muscle Atrophy: A Study of Hindlimb-Unweighted Rats. Arch Phys Med Rehabil 82: 930-934.

30. Apseloff G, Grirten B, Walker M, Shepard DR, Krecic ME, et al. (1993) Aminohydroxybutane Bisphosphonate and Clenbuterol Prevent Bone Changes and Retard Muscle Atrophy Respectively in TailSuspended Rats. J Pharmacol Exp Ther 264: 1071-1078.

31. Maltin CA, Delday MI, Campbell SP, Hesketh JE (1993) Clenbuterol Mimics Effects of Innervation on Myogenic Regulatory Factor Expression. Am J Physiol 265: E176-E178.

32. Maltin CA, Hay SM, Delday MI, Smith FG, Lobley GE, et al. (1987) Clenbuterol, a Beta Agonist, Induces Growth in Innervated and Denervated Rat Soleus Muscle via Apparently Different Mechanisms. Biosci Rep 7: 525-531.

33. Sneddon AA, Delday MI, Maltin CA (2000) Amelioration of Denervation-Induced Atrophy by Clenbuterol Is Associated With Increased PKC-alpha Activity. Am J Physiol Endocrinol Metab 279: E188-E195.

34. Beitzel F, Gregorevic P, Ryall JG, Plant DR, Sillence MN, et al. (2003) Beta2-adrenoceptor Agonist Fenoterol Enhances Functional Repair of Regenerating Rat Skeletal Muscle After Injury. J Appl Physiol 96: 1385-1392.

35. Ryall JG, Plant DR, Gregorevic P, Sillence MN, Lynch GS (2004) Beta 2-agonist Administration Reverses Muscle Wasting and Improves Muscle Function in Aged Rats. J Physiol 555: 175-188.

36. Maltin CA, Delday MI, Watson JS, Heys SD, Nevison IM, et al. (1993) Clenbuterol, a Beta-Adrenoceptor Agonist, Increases Relative Muscle Strength in Orthopaedic Patients. Clin Sci (Lond) 84: 651654

37. Signorile JF, Banovac K, Gomez M, Flipse D, Caruso JF, et al. (1995) Increased Muscle Strength in Paralyzed Patients After Spinal Cord Injury: Effect of beta-2 Adrenergic Agonist. Arch Phys Med Rehabil 76: 55-58.

38. Kissel JT, McDermott MP, Mendell JR, King WM, Pandya S, et al. (2001) Randomized, Double-Blind, Placebo-Controlled Trial of Albuterol in Facioscapulohumeral Dystrophy. Neurology 57: 14341440.

39. Gregorevic P, Ryall JG, Plant DR, Sillence MN, Lynch GS (2005) Chronic Beta-Agonist Administration Affects Cardiac Function of Adult but not Old Rats, Independent of Beta-Adrenoceptor Density. Am J Physiol Heart Circ Physiol 289: H344-H349.

40. Duncan ND, Williams DA, Lynch GS (2000) Deleterious Effects of Chronic Clenbuterol Treatment on Endurance and Sprint Exercise Performance in Rats. Clin Sci (Lond) 98: 339-345.

41. Carbo N, Lopez-Soriano J, Tarrago T, Gonzalez O, Llovera M, et al. (1997) Comparative effects of beta2-adrenergic agonists on muscle waste associated with tumour growth. Cancer Lett 115: 113-118.

42. Chen KD, Alway SE (1985) A physiological level of clenbuterol does not prevent atrophy or loss of force in skeletal muscle of old rats. J Appl Physiol 89: 606-612.

43. Fowler EG, Graves MC, Wetzel GT, Spencer MJ (2004) Pilot trial of albuterol in Duchenne and Becker muscular dystrophy. Neurology 62: 1006-1008.
44. Guhan A, Cooper S, Oborne J, Lewis S, Bennett J, et al. (2000) Systemic effects of formoterol and salmeterol: a dose-response comparison in healthy subjects. Thorax 55: 650-656.

45. Waldeck B (1996) Some pharmacodynamic aspects of long-acting beta-adrenoceptor agonists. Gen Pharmacol 27: 575-580.

46. Pepicelli A, Woods M, Briggs C (2005) The mandibular muscles and their importance in orthodontics: a contemporary review. Am J Orthod Dentofacial Orthop 128: 774-780.

47. Lim D, Beitzel F, Lynch G, Woods MG (2006) Myosin heavy chain isoform composition of human masseter muscle from subjects with different mandibular plane angles. Aust Orthod J 22: 105-114.

48. Chan HJ, Woods M, Stella D (2007) Three-dimensional computed craniofacial tomography (3D-CT): potential uses and limitations. Aust Orthod J 23: 55-64.

49. Chan HJ, Woods M, Stella D (2008) Mandibular muscle morphology in children with different vertical facial patterns: A 3-dimensional computed tomography study. Am J Orthod Dentofacial Orthop 133: e1-e13.

50. Wong A, Woods MG, Stella D (2016) Three-dimensional computed tomographic assessment of mandibular muscles in growing subjects with different vertical facial patterns. Aust Orthod J 32: 2-17.

51. Fitzpatrick B, Woods M, Lynch G, Manton D (2014) Denervation and beta2-adrenoceptor agonist administration on craniofacial bone density. Aust Orthod J 30: 32-38.

52. Fitzpatrick B, Woods M, Lynch G, Manton D (2014) The effects of denervation and formoterol administration on facial growth. Aust Orthod J 30: 161-168.

53. Mayne RJ, Van Der Poel C, Woods MG, Lynch GS (2015) Skeletal effects of the alteration of masseter muscle function. Aust Orthod J 31: 184-194.

54. Segal SS, Faulkner JA (1985) Temperature-dependent physiologica stability of rat skeletal muscle in vitro. Am J Physiol 248: C265-270.

55. Brooks SV, Faulkner JA (1988) Contractile properties of skeletal muscles from young, adult and aged mice. J Physiol 404: 71-82.

56. Mendez J, Keys A (1960) Density and composition of mammalian muscle. Metabolism 9: 184-188.

57. Goldspink DF, Garlick PJ, McNurlan MA (1983) Protein turnover measured in vivo and in vitro in muscles undergoing compensatory growth and subsequent denervation atrophy. Biochem J 210: 89-98.

58. Hinkle RT, Hodge KM, Cody DB, Sheldon RJ, Kobilka BK, et al. (2002) Skeletal muscle hypertrophy and anti-atrophy effects of clenbuterol are mediated by the beat2-adrenergic receptor. Muscle Nerve 25: 729-734.

59. Busquets S, Figueras MT, Fuster G, Almendro V, Moore-Carrasco $R$, et al. (2004) Anticachectic effects of formoterol: a drug for the potential treatment of muscle wasting. Cancer Res 64: 6725-6731.

60. Germinario E, Esposito A, Megighian A, Midrio M, Biral D, et al. (2002) Early changes of type 2B fibers after denervation of rat EDL skeletal muscle. J Appl Physiol 92: 2045-2052.

61. Lamb GD, Junankar PR, Stephenson DG (1995) Raised intracellular [Ca2+] abolishes excitation-contraction coupling in skeletal muscle fibres of rat and toad. J Physiol 489: 349-362. 